\title{
On Stable and Strategy-Proof Rules in Matching Markets with Contracts
}

\author{
Daisuke Hirata* \\ Hitotsubashi University \\ Yusuke Kasuya $^{\dagger}$
Yokohama National University
}

This Version: September 25, 2015

\author{
Hitotsubashi University \\ Graduate School of Economics \\ Discussion Paper No. 2015-10
}

\begin{abstract}
This paper studies stable and (one-sided) strategy-proof matching rules in manyto-one matching markets with contracts. First, the number of such rules is shown to be at most one. Second, the doctor-optimal stable rule, whenever it exists, is shown to be the unique candidate for a stable and strategy-proof rule. Third, a stable and strategyproof rule, when exists, is shown to be second-best optimal for doctor welfare, in the sense that no individually-rational and strategy-proof rule can dominate it. This last result is further generalized to non-wasteful and strategy-proof rules. Notably, all those results are established without any substitutes conditions on hospitals' choice functions, and hence, the proofs do not rely on the "rural hospital" theorem. We also show by example that the outcomes of a stable and strategy-proof rule do not always coincide with those of the cumulative offer process; hence, the above results hold not because the cumulative offer process is the only candidate for stable and strategyproof rules.
\end{abstract}

Keywords: matching with contracts, stability, strategy-proofness, uniqueness, efficiency, irrelevance of rejected contracts

*Email: d.hirata@r.hit-u.ac.jp

†Email: yusuke.asia@gmail.com 


\section{Introduction}

Since its birth by Gale and Shapley (1962), the theory of two-sided matching markets has been centered around the deferred acceptance algorithm, which is known to satisfy a number of desiderata. Specifically, in the classic setup, it is not only stable but also (onesided) strategy-proof (Dubins and Freedman, 1981; Roth, 1982), and moreover, it is the unique such rule (Alcalde and Barberà, 1994). More recently, Hatfield and Milgrom (2005) propose a more general model of matching with contracts and, among many other things, verify that the deferred acceptance is stable and strategy-proof under certain conditions, called substitutable contracts and the law of aggregated demand. ${ }^{1}$ With those conditions, Sakai (2011) also generalizes the uniqueness result and hence, the study of stable and strategy-proof rules is necessarily the study of the deferred acceptance. At the same time, however, the rapid developments of the matching with contracts literature has started to cover, in both theory and practice, the cases that violate those pre-known conditions for the deferred acceptance to be stable and/or strategy-proof (e.g., Dimakopoulos and Heller, 2014; Hatfield and Kojima, 2010; Kominers and Sönmez, 2013, 2014).

With those developments in mind, the purpose of this paper is to study stable and (one-sided) strategy-proof rules as generally as possible, and to disentangle some nature of such rules that arises purely from the two properties. Specifically, our results only require the choice functions on the hospital side to satisfy the irrelevance of rejected contracts (henceforth, IRC) condition, which is a very mild rationality requirement, but not any kind of "substitutes" condition.

The first and second results (Theorems 1-2) are on the uniqueness of stable and strategyproof rules and extend the existing results mentioned above: Theorem 1 states that the number of such rules is at most one in general (as long as the IRC condition is satis-

\footnotetext{
${ }^{1}$ See Definitions 1 and 4 in Appendix A for the definitions of those conditions.
} 
fied), although there may or may not exist one without additional restrictions. Further, Theorem 2 establishes that the doctor-optimal stable rule is the unique candidate for a stable and strategy-proof rule, whenever it is well-defined, although it may or may not be strategy-proof without additional assumptions. From the technical point of view, it is noteworthy that our proofs of Theorems 1-2 do not rely on the rural hospital theorem, which has been playing a central role in the existing studies on stable and strategy-proof rules. ${ }^{2}$ Instead, our proofs exploit a weaker property of stable allocations, which follows solely from the IRC condition, and shed new light on the fundamental tension between stability and strategy-proofness.

Our last main result, Theorem 3, is on the constrained optimality of a stable and strategy-proof rule. Namely, we show (again, under the IRC condition) that a stable and strategy-proof rule, if exists, is never dominated in terms of doctor welfare by any other individually rational and strategy-proof rule. Further, we also show in an appendix that the same holds true even if stability is weakened to non-wastefulness in the above statement (Theorem 4). These theorems (partially) generalize similar existing results in the school choice literature (e.g., Abdulkadiroglu et al., 2009; Kesten, 2010; Kesten and Kurino, 2013).

The rest of this paper is organized as follows. Section 2 describes the model and introduces key concepts. Section 3 provides the results. Section 4 concludes. Appendix A introduces a number of definitions that are omitted in the main text but useful to relate our results to the literature. Appendix B presents two variants of Theorem 3. Appendix C contains examples.

\footnotetext{
${ }^{2}$ See the discussion after Corollary 2 for details.
} 


\section{Preliminaries}

We study the standard setting of a many-to-one matching market with contracts. Let $D$ and $H$ be finite sets of doctors and hospitals, respectively. The finite set of possible contracts is given by $X \subset D \times H \times \Theta$ for some $\Theta .{ }^{3}$ For each contract $x \in X$, let $\mathrm{d}(x)$ and $\mathrm{h}(x)$ be its projections onto $D$ and $H$, i.e., $x=(\mathrm{d}(x), \mathrm{h}(x), \theta)$ for some $\theta \in \Theta$. In other words, $x$ is a bilateral contract between $\mathrm{d}(x) \in D$ and $\mathrm{h}(x) \in H$.

A subset $X^{\prime} \subset X$ of contracts is said to be an allocation if it includes at most one contract for each doctor, i.e., if $x, x^{\prime} \in X^{\prime}$ and $x \neq x^{\prime}$ imply $\mathrm{d}(x) \neq \mathrm{d}\left(x^{\prime}\right)$. The set of all possible allocations is denoted by $\mathscr{X} \subset 2^{X}$. For each allocation $X^{\prime} \in \mathscr{X}$ and doctor $d \in D$, let $\mathrm{x}\left(d, X^{\prime}\right)$ denote the contract that $X^{\prime}$ assigns to $d$; i.e., $\mathrm{x}\left(d, X^{\prime}\right)=x$ if $x \in X^{\prime}$ and $\mathrm{d}(x)=d$. If there is no such contract in $X^{\prime}$, doctor $d$ is said to be assigned a null-contract and we write $\mathrm{x}\left(d, X^{\prime}\right)=\varnothing$. Similarly, let $\mathrm{X}\left(h, X^{\prime}\right)=\left\{x \in X^{\prime}: \mathrm{h}(x)=h\right\}$ be the set of (non-null) contracts that $X^{\prime}$ assigns to hospital $h \in H$.

Each doctor $d \in D$ has a strict preference relation $\succ_{d}$ over $\{x \in X: \mathrm{d}(x)=d\} \cup\{\varnothing\}$. The domain of all possible preferences for doctor $d$ is denoted by $\mathscr{P}_{d}$. Given his preference relation $\succ_{d}$, a non-null contract $x$ is said to be acceptable to doctor $d$ if $x \succ_{d} \varnothing$. The set of acceptable contracts to doctor $d$, as a function of $\succ_{d}$, is given by

$$
\operatorname{Ac}\left(\succ_{d}\right):=\left\{x \in X: \mathrm{d}(x)=d \text { and } x \succ_{d} \varnothing\right\}
$$

The profile of the doctors' preference relations is denoted by $\succ_{D}=\left(\succ_{d}\right)_{d \in D}$. Let $\mathscr{P}_{D}:=$ $\prod_{d \in D} \mathscr{P}_{d}$ be the domain of all possible preference profiles. Each hospital $h \in H$ has a choice function $C_{h}: 2^{X} \rightarrow \mathscr{X}$ such that for all $X^{\prime} \subset X$, (i) $C_{h}\left(X^{\prime}\right) \in 2^{X^{\prime}} \cap \mathscr{X}$ and (ii) $\mathrm{h}(x)=h$ for all $x \in C_{h}\left(X^{\prime}\right)$. Throughout the paper, we assume that the choice func-

\footnotetext{
${ }^{3}$ For example, $\Theta$ can be interpreted as the set of possible wage levels (Kelso and Crawford, 1982) and/or job descriptions (Roth, 1984).

${ }^{4}$ Note that $x \succ_{d} \varnothing$ implies $\mathrm{d}(x)=d$ since $\succ_{d}$ is defined over $\{x \in X: \mathrm{d}(x)=d\} \cup\{\varnothing\}$.
} 
tions satisfy the following mild requirement: Hospital $h$ 's choice function $C_{h}(\cdot)$ is said to satisfy the irrelevance of rejected contracts (henceforth, IRC) condition if $x \notin C_{h}\left(X^{\prime} \cup\{x\}\right)$ implies $C_{h}\left(X^{\prime} \cup\{x\}\right)=C_{h}\left(X^{\prime}\right)$ for all $X^{\prime} \subset X$ and $x \in X .{ }^{5}$ The profile of the hospitals' choice functions is denoted by $C_{H}(\cdot)=\left(C_{h}(\cdot)\right)_{h \in H}$.

Given $\succ_{D}$ and $C_{H}(\cdot)$, we define the following concepts on $\mathscr{X}$ : An allocation $X^{\prime} \in \mathscr{X}$ is said to be individually rational if (i) $x\left(d ; X^{\prime}\right) \succeq_{d} \varnothing$ for all $d \in D$, and (ii) $C_{h}\left(X^{\prime}\right)=\mathrm{X}\left(h, X^{\prime}\right)$ for all $h \in H$. A pair of a hospital $h \in H$ and a subset $X^{\prime \prime} \subset X$ of contracts is said to block an allocation $X^{\prime}$ if (i) $C_{h}\left(X^{\prime} \cup X^{\prime \prime}\right)=X^{\prime \prime} \neq C_{h}\left(X^{\prime}\right)$ and (ii) $\mathrm{x}\left(d, C_{h}\left(X^{\prime} \cup X^{\prime \prime}\right)\right) \succeq_{d} \times\left(d, X^{\prime}\right)$ for all $d \in\{\mathrm{d}(x)\}_{x \in C_{h}\left(X^{\prime} \cup X^{\prime \prime}\right)}$. An allocation $X^{\prime}$ is said to be stable if it is individually rational and not blocked by any $\left(h, X^{\prime \prime}\right) \in H \times 2^{X}$. An allocation $X^{\prime}$ is said to strictly dominate another allocation $X^{\prime \prime} \neq X^{\prime}$ if $\mathrm{x}\left(d, X^{\prime}\right) \succeq_{d} \times\left(d, X^{\prime \prime}\right)$ for all $d \in D .^{6}$ A stable allocation $X^{*}$ is said to be doctor-optimal if it strictly dominates any other stable allocation.

Given $C_{H}(\cdot)$ as well as $(D, H, X)$, a matching rule is a mapping $f: \mathscr{P}_{D} \rightarrow \mathscr{X}$, which associates each possible preference profile of doctors with an allocation. A rule $f(\cdot)$ is said to be stable (resp. individually rational) if for all $\succ_{D} \in \mathscr{P}_{D}$, its output $f\left(\succ_{D}\right)$ is stable (resp. individually rational) with respect to $\left(C_{H}(\cdot), \succ_{D}\right)$. Similarly, the doctor-optimal stable rule, denoted by $X^{*}(\cdot)$ if exists, is a rule such that for all $\succ_{D} \in \mathscr{P}_{D}$, its output $X^{*}\left(\succ_{D}\right)$ is the doctor-optimal stable allocation with respect to $\left(C_{H}(\cdot), \succ_{D}\right)$. A rule $f(\cdot)$ is said to strictly dominate another rule $g(\cdot) \neq f(\cdot)$ if $\mathrm{x}\left(d, f\left(\succ_{D}\right)\right) \succeq_{d} \times\left(d, g\left(\succ_{D}\right)\right)$ for all $d \in D$ and $\succ_{D} \in \mathscr{P}_{D}{ }^{7}$ Finally, a rule $f(\cdot)$ is said to be strategy-proof if $\mathrm{x}\left(d, f\left(\succ_{D}\right)\right) \succeq_{d}$ $\mathrm{x}\left(d, f\left(\succ_{d^{\prime}}^{\prime} \succ_{D-\{d\}}\right)\right)$ for all $d \in D, \succ_{D} \in \mathscr{P}_{D}$, and $\succ_{d}^{\prime} \in \mathscr{P}_{d}$, where $\succ_{D-\{d\}}=\left(\succ_{d^{\prime}}\right)_{d^{\prime} \in D-\{d\}}$.

\footnotetext{
${ }^{5}$ Aygün and Sönmez $(2012,2013)$ point out the importance of this condition, which is implicitly assumed in Hatfield and Milgrom (2005) and Hatfield and Kojima (2010). Note that this condition is satisfied if a choice function is induced by a strict preference over subsets of contracts (as in some of the examples below).

${ }^{6}$ Note that $X^{\prime} \neq X^{\prime \prime}$ and $\mathrm{x}\left(d, X^{\prime}\right) \succeq_{d} \times\left(d, X^{\prime \prime}\right)$ for all $d$ imply $\mathrm{x}\left(d^{\prime}, X^{\prime}\right) \succ_{d^{\prime}} \times\left(d^{\prime}, X^{\prime \prime}\right)$ for some $d^{\prime}$.

${ }^{7}$ Again, $g(\cdot) \neq f(\cdot)$ implies $\mathrm{x}\left(d^{\prime}, f\left(\succ_{D}\right)\right) \succ_{d^{\prime}} \mathrm{x}\left(d^{\prime}, g\left(\succ_{D}\right)\right)$ for some $d^{\prime}$ and $\succ_{D}$ if $f(\cdot)$ strictly dominates $g(\cdot)$
} 


\section{Results}

To start our analysis, we introduce the following weaker notion of blocking coalitions: We say that a pair $\left(h, X^{\prime \prime}\right) \in H \times 2^{X}$ weakly blocks an allocation $X^{\prime}$ if (i) $C_{h}\left(X^{\prime} \cup X^{\prime \prime}\right) \neq C_{h}\left(X^{\prime}\right)$ and (ii) $\mathrm{x}\left(d, C_{h}\left(X^{\prime} \cup X^{\prime \prime}\right)\right) \succeq_{d} \mathrm{x}\left(d, X^{\prime}\right)$ for all $d \in\{\mathrm{d}(x)\}_{x \in C_{h}\left(X^{\prime} \cup X^{\prime \prime}\right)}$. This definition is weak in that the first part does not require $C_{h}\left(X^{\prime} \cup X^{\prime \prime}\right)=X^{\prime \prime}$. Under the IRC condition, however, it is straightforward to verify that the two blocking concepts are equally effective in the following sense.

Lemma 1. Suppose that hospital h's choice function $C_{h}(\cdot)$ satisfies the IRC condition. For any allocation $X^{\prime} \in \mathscr{X}$, then, there exists $X^{\prime \prime} \subset X$ such that $\left(h, X^{\prime \prime}\right)$ blocks $X^{\prime}$ if and only if there exists $X^{\prime \prime \prime} \subset X$ such that $\left(h, X^{\prime \prime \prime}\right)$ weakly blocks $X^{\prime}$.

Proof. The "only if" part is immediate from the definitions. To see the "if" part, suppose that $\left(h, X^{\prime \prime \prime}\right)$ weakly blocks $X^{\prime}$, and let $X^{\prime \prime}:=C_{h}\left(X^{\prime} \cup X^{\prime \prime \prime}\right)$. Then, the IRC condition implies $C_{h}\left(X^{\prime} \cup X^{\prime \prime}\right)=C_{h}\left(X^{\prime} \cup X^{\prime \prime \prime}\right)=X^{\prime \prime}$ and hence, the first requirement for $\left(h, X^{\prime \prime}\right)$ to block $X^{\prime}$ is satisfied. The second requirement is also trivially satisfied by the assumption that $\left(h, X^{\prime \prime \prime}\right)$ weakly blocks $X^{\prime}$.

Lemma 1 leads to the following observation, which will be the key in the proofs of Theorems 1-2.

Lemma 2. Suppose that every hospital $h \in H$ has a choice function $C_{h}(\cdot)$ satisfying the IRC condition, and that $X^{\prime}$ and $X^{\prime \prime}$ are two distinct stable allocations at $\left(C_{H}, \succ_{D}\right)$. Then, there exists a doctor $d \in D$ who is assigned distinct non-null contracts by $X^{\prime}$ and $X^{\prime \prime}$, i.e., $\varnothing \neq \mathrm{x}\left(d, X^{\prime}\right) \neq$ $\mathrm{x}\left(d, X^{\prime \prime}\right) \neq \varnothing$.

Proof. The proof is by contraposition. Assume the negation of the consequent, i.e.,

$$
\left[\mathrm{x}\left(d, X^{\prime}\right) \neq \mathrm{x}\left(d, X^{\prime \prime}\right)\right] \Longrightarrow\left[\varnothing \in\left\{\mathrm{x}\left(d, X^{\prime}\right), \mathrm{x}\left(d, X^{\prime \prime}\right)\right\}\right], \text { for all } d \in D
$$


where $X^{\prime}$ and $X^{\prime \prime}$ are two (possibly identical) stable allocations at $\left(C_{H}(\cdot), \succ_{D}\right)$. Since $X^{\prime \prime}$ is stable (and thus individually rational), this implies for all $d \in D$,

$$
\left[\mathrm{x}\left(d, X^{\prime \prime}\right) \neq \varnothing\right] \Longrightarrow\left[\mathrm{x}\left(d, X^{\prime \prime}\right) \succ_{d} \varnothing=\mathrm{x}\left(d, X^{\prime}\right) \text { or } \mathrm{x}\left(d, X^{\prime}\right)=\mathrm{x}\left(d, X^{\prime \prime}\right)\right]
$$

and hence,

$$
\left[\mathrm{x}\left(d, X^{\prime \prime}\right) \neq \varnothing\right] \Longrightarrow\left[\mathrm{x}\left(d, X^{\prime \prime}\right) \succeq_{d} \mathrm{x}\left(d, X^{\prime}\right)\right]
$$

For an arbitrary hospital $h \in H$, then, $\left(h, X^{\prime \prime}\right)$ satisfies the second requirement to weakly block $X^{\prime}$. Since $\left(h, X^{\prime \prime}\right)$ cannot weakly block $X^{\prime}$ by stability and Lemma 1 , it must violate the first requirement; i.e., $C_{h}\left(X^{\prime} \cup X^{\prime \prime}\right)=X\left(h, X^{\prime}\right)$ must hold. As the symmetric arguments also imply $C_{h}\left(X^{\prime} \cup X^{\prime \prime}\right)=\mathrm{X}\left(h, X^{\prime \prime}\right)$ for all $h \in H$, it follows that $\mathrm{X}\left(h, X^{\prime}\right)=$ $X\left(h, X^{\prime \prime}\right)$ for all $h \in H$ and thus $X^{\prime}=X^{\prime \prime}$.

Our first main result generalizes the existing results on the uniqueness of a stable and strategy-proof rule by Alcalde and Barberà (1994, Theorem 3) and Sakai (2011, Theorem 1). While this theorem does not require any substitutes condition, its proof depends on Lemma 2, which in turn necessitates the IRC condition. See Example 1 in Appendix $C$ for a counterexample in the absence of the IRC condition.

Theorem 1. Suppose that every hospital $h \in H$ has a choice function $C_{h}(\cdot)$ satisfying the IRC condition. Then, there exists at most one stable and strategy-proof rule; i.e., if $f(\cdot)$ and $g(\cdot)$ are both stable and strategy-proof, $f\left(\succ_{D}\right)=g\left(\succ_{D}\right)$ for all $\succ_{D} \in \mathscr{P}_{D}$.

Proof. Towards a contradiction, suppose that there exist two distinct stable and strategyproof rules, $f(\cdot)$ and $g(\cdot)$. Let $\succ_{D}^{*} \in \mathscr{P}_{D}$ be a preference profile such that $f\left(\succ_{D}^{*}\right) \neq g\left(\succ_{D}^{*}\right)$ 
and

$$
\left[f\left(\succ_{D}\right) \neq g\left(\succ_{D}\right) \Longrightarrow \sum_{d \in D}\left|\operatorname{Ac}\left(\succ_{d}\right)\right| \geq \sum_{d \in D}\left|\operatorname{Ac}\left(\succ_{d}^{*}\right)\right|\right] \text { for all } \succ_{D} \in \mathscr{P}_{D}
$$

which exists by assumption. Then, by Lemma 2, there must exist a doctor $d^{*}$ such that $\varnothing \neq \mathrm{x}\left(d^{*}, f\left(\succ_{D}^{*}\right)\right) \neq \mathrm{x}\left(d^{*}, g\left(\succ_{D}^{*}\right)\right) \neq \varnothing$. Note that this also implies $\left|\operatorname{Ac}\left(\succ_{d^{*}}^{*}\right)\right| \geq 2$.

Now, suppose without loss of generality that $\mathrm{x}\left(d^{*}, f\left(\succ_{D}^{*}\right)\right) \succ_{d^{*}}^{*} \mathrm{x}\left(d^{*}, g\left(\succ_{D}^{*}\right)\right)$, and let $\succ_{D}^{* *}:=\left(\succ_{d^{*}}^{* *} \succ_{D-\left\{d^{*}\right\}}^{*}\right)$, where $\succ_{d^{*}}^{* *}$ is a preference relation of doctor $d^{*}$ such that only $\mathrm{x}\left(d^{*}, f\left(\succ_{D}^{*}\right)\right)$ is acceptable, i.e., $\operatorname{Ac}\left(\succ_{d^{*}}^{* *}\right)=\left\{\mathrm{x}\left(d^{*}, f\left(\succ_{D}^{*}\right)\right)\right\}$. Notice that

$$
\mathrm{x}\left(d^{*}, f\left(\succ_{D}^{* *}\right)\right), \mathrm{x}\left(d^{*}, g\left(\succ_{D}^{* *}\right)\right) \in\left\{\mathrm{x}\left(d^{*}, f\left(\succ_{D}^{*}\right)\right), \varnothing\right\}
$$

since $f(\cdot)$ is assumed to be stable (and hence individually rational). Then, the strategyproofness of $f(\cdot)$ and $g(\cdot)$ implies

$$
\begin{array}{r}
\mathrm{x}\left(d^{*}, f\left(\succ_{D}^{* *}\right)\right)=\mathrm{x}\left(d^{*}, f\left(\succ_{D}^{*}\right)\right), \text { and } \\
\varnothing=\mathrm{x}\left(d^{*}, g\left(\succ_{D}^{* *}\right)\right) \neq \mathrm{x}\left(d^{*}, g\left(\succ_{D}^{*}\right)\right),
\end{array}
$$

respectively, and hence, $f\left(\succ_{D}^{* *}\right) \neq g\left(\succ_{D}^{* *}\right)$. This, however, contradicts the definition of $\succ_{D^{\prime}}^{*}$, since $\left|\operatorname{Ac}\left(\succ_{d^{*}}^{* *}\right)\right|=1<2 \leq\left|\operatorname{Ac}\left(\succ_{d^{*}}^{*}\right)\right|$ and $\succ_{D-\left\{d^{*}\right\}}^{* *}=\succ_{D-\left\{d^{*}\right\}}^{*}$, and the proof is complete.

Theorem 1, together with the results by Kominers and Sönmez $(2013,2014)$, immediately entails the following corollary. ${ }^{8}$

Corollary 1. Suppose that every hospital $h \in H$ has a choice function $C_{h}(\cdot)$ that is induced by some slot-specific priorities. Then, the cumulative offer process induces the unique stable and

\footnotetext{
${ }^{8}$ See Definitions 5 and 6 in Appendix A for the definitions of slot-specific priorities and the cumulative offer process.
} 
strategy-proof rule.

Proof. In the case of slot-specific priorities, Kominers and Sönmez $(2013,2014)$ show that the rule induced by the cumulative offer process is both stable and strategy-proof. The uniqueness follows from Theorem 1.

Following the same line of proof, we can also show that whenever it exists, the doctoroptimal stable rule is the unique candidate for a stable and strategy rule. Note, however, that this unique candidate may or may not be strategy-proof without additional assumptions.

Theorem 2. Suppose that every hospital $h \in H$ has a choice function $C_{h}(\cdot)$ satisfying the IRC condition, and that the doctor-optimal stable allocation $X^{*}\left(\succ_{D}\right)$ exists for all $\succ_{D} \in \mathscr{P}_{D}$. If $f(\cdot)$ is a stable and strategy-proof rule, then, $f\left(\succ_{D}\right)=X^{*}\left(\succ_{D}\right)$ for all $\succ_{D} \in \mathscr{P}_{D}$.

Proof. Towards a contradiction, suppose that the doctor-optimal stable rule $X^{*}(\cdot)$ is welldefined, and that $f(\cdot) \neq X^{*}(\cdot)$ is a stable and strategy-proof rule. Let $\succ_{D}^{*} \in \mathscr{P}_{D}$ be a preference profile such that $f\left(\succ_{D}^{*}\right) \neq X^{*}\left(\succ_{D}^{*}\right)$ and

$$
\left[f\left(\succ_{D}\right) \neq X^{*}\left(\succ_{D}\right) \Longrightarrow \sum_{d \in D}\left|\operatorname{Ac}\left(\succ_{d}\right)\right| \geq \sum_{d \in D}\left|\operatorname{Ac}\left(\succ_{d}^{*}\right)\right|\right] \text { for all } \succ_{D} \in \mathscr{P}_{D},
$$

which exists by assumption. Then, by Lemma 2, there must exist a doctor $d^{*}$ such that $\varnothing \neq \mathrm{x}\left(d^{*}, f\left(\succ_{D}^{*}\right)\right) \neq \mathrm{x}\left(d^{*}, X^{*}\left(\succ_{D}^{*}\right)\right) \neq \varnothing$. Note that this also implies $\mathrm{x}\left(d^{*}, X^{*}\left(\succ_{D}^{*}\right)\right) \succ_{d^{*}}^{*}$ $\mathrm{x}\left(d^{*}, f\left(\succ_{D}^{*}\right)\right) \succ_{d^{*}}^{*} \varnothing$.

Now let $\succ_{D}^{* *}:=\left(\succ_{d^{*}}^{*}, \succ_{D-\left\{d^{*}\right\}}^{*}\right)$, where $\succ_{d^{*}}^{* *}$ is a truncation of $\succ_{d^{*}}^{*}$ at $x\left(d^{*}, X^{*}\left(\succ_{D}^{*}\right)\right)$, i.e., a preference relation such that

$$
\operatorname{Ac}\left(\succ_{d^{*}}^{* *}\right)=\left\{x \in X: x \succeq_{d^{*}}^{*} \mathrm{x}\left(d^{*}, X^{*}\left(\succ_{D}^{*}\right)\right)\right\}
$$


and

$$
\left[x \succ_{d^{*}}^{* *} y \Longleftrightarrow x \succ_{d^{*}}^{*} y\right] \text { for all } x, y \in \operatorname{Ac}\left(\succ_{d^{*}}^{* *}\right)
$$

Notice that $X^{*}\left(\succ_{D}^{* *}\right)=X^{*}\left(\succ_{D}^{*}\right)$ by construction. ${ }^{9}$ Together with the strategy-proofness of $f(\cdot)$, this further implies

$$
\mathrm{x}\left(d^{*}, X^{*}\left(\succ_{D}^{* *}\right)\right)=\mathrm{x}\left(d^{*}, X^{*}\left(\succ_{D}^{*}\right)\right) \succ_{d^{*}}^{*} \mathrm{x}\left(d^{*}, f\left(\succ_{D}^{*}\right)\right) \succeq_{d^{*}}^{*} \mathrm{x}\left(d_{1}, f\left(\succ_{D}^{* *}\right)\right),
$$

and hence, $f\left(\succ_{D}^{* *}\right) \neq X^{*}\left(\succ_{D}^{* *}\right)$. This, however, contradicts the definition of $\succ_{D}^{*}$, since $\operatorname{Ac}\left(\succ_{d^{*}}^{* *}\right) \subset \operatorname{Ac}\left(\succ_{d^{*}}^{*}\right)-\left\{x\left(d^{*}, f\left(\succ_{D}^{*}\right)\right)\right\}$ and $\succ_{D-\left\{d^{*}\right\}}^{* *}=\succ_{D-\left\{d^{*}\right\}}^{*}$, and the proof is complete.

Along with Theorem 5 of Hatfield and Kojima (2010), Theorem 2 leads to the following corollary. ${ }^{10}$

Corollary 2. Suppose that every hospital $h \in H$ has a choice function $C_{h}(\cdot)$ satisfying the unilateral substitutes condition and the IRC condition. Then, if a stable and strategy-proof rule exists, it is induced by the doctor-proposing deferred acceptance algorithm. ${ }^{11}$

Proof. Under the supposition, a doctor-optimal stable allocation always exists and is induced by the doctor-proposing deferred acceptance algorithm (Hatfield and Kojima, 2010, Theorem 5). ${ }^{12}$ Hence, the claim immediately follows from Theorem 2.

\footnotetext{
${ }^{9}$ To see this, note first that any stable allocation at $\succ_{D}^{*}$, including $X^{*}\left(\succ_{D}^{*}\right)$, is also stable at $\succ_{D}^{* *}$. For $X^{*}\left(\succ_{D}^{* *}\right) \neq X^{*}\left(\succ_{D}^{*}\right)$ to hold, therefore, $X^{*}\left(\succ_{D}^{* *}\right)$ cannot be stable at $\succ_{D}^{*}$. Yet, $\mathrm{x}\left(d^{*}, X^{*}\left(\succ_{D}^{* *}\right)\right)=\varnothing$ must hold if $\left(h, X^{\prime}\right)$ blocks $X^{*}\left(\succ_{D}^{* *}\right)$ at $\succ_{D}^{*}$ but not at $\succ_{D}^{* *}$. Since $x\left(d^{*}, X^{*}\left(\succ_{D}^{*}\right)\right) \succ_{d^{*}}^{* *} \varnothing$, this means that $X^{*}\left(\succ_{D}^{* *}\right)$ cannot dominate $X^{*}\left(\succ_{D}^{*}\right)$ at $\succ_{D}^{* *}$, which is a contradiction.

${ }^{10}$ See Definition 2 in Appendix A for the definition of unilateral substitutes.

${ }^{11}$ Under the same conditions, an independent paper by Afacan (2015) characterizes the deferred acceptance as the unique stable rule that cannot be manipulated by "truncations," although it may not be fully strategy-proof.

${ }^{12}$ See also Aygün and Sönmez (2012, Thorem 5).
} 
Compared to the existing uniqueness results, Theorems 1-2 above are technically novel for two related reasons. First, our proof of Theorem 1 requires no dominance relation between $f(\cdot)$ and $g(\cdot)$. Consequently, it is applicable even when the doctor-optimal stable allocation does not always exist. In contrast, the uniqueness results by Alcalde and Barberà (1994, Theorem 3) and Sakai (2011, Theorem 1) are established by showing any stable rule that is strictly dominated by the doctor-optimal stable rule cannot be strategyproof and hence, the existence of the doctor-optimal stable rule is critical in their proofs. Second, our proofs do not call for the rural hospital theorem either, which states that every agent (i.e., every doctor and every hospital) signs the same number of non-null contracts across all stable allocations. Instead we utilize Lemma 2, which could be seen as a weaker version of the rural hospital theorem but holds true without any restrictions on $C_{H}(\cdot)$ other than the IRC condition. ${ }^{13}$ It is this distinction that makes the proof of Theorem 2 non-trivial, although its statement might look very close to the previous results.

Given the second point in the previous paragraph, one might wonder if the doctoroptimal stable rule can be strategy-proof even when the rural hospital theorem fails to hold. Theorem 2 would be vacuous if there is no such case, since the doctor-optimal stable rule can be shown to be strategy-proof whenever the rural hospital theorem holds. ${ }^{14}$ Indeed, there exist such cases and hence, Theorem 2 applies to a strictly larger domain of choice functions than the previous results.

Fact 1. The doctor-optimal stable rule can be strategy-proof even if there exists a preference profile such that not all doctors sign the same number of non-null contracts across all stable allocations (and hence, even if the rural hospital theorem fails to hold).

Proof. The proof is by example. Suppose that $D=\left\{d_{1}, d_{2}, d_{3}\right\}, H=\left\{h, h^{\prime}\right\}$, and $X=$ $\left\{x_{i}, x_{i}^{\prime}\right\}_{i \in\{1,2,3\}}$, where $x_{i}$ (resp. $x_{i}^{\prime}$ ) represents a contract between doctor $d_{i}$ and hospital $h$

\footnotetext{
${ }^{13}$ Note that the conclusion of Lemma 2 immediately follows if the rural hospital theorem holds.

${ }^{14}$ See the proofs of Hatfield and Kojima (2010, Theorem 7) and Hatfield and Milgrom (2005, Theorem 11).
} 
(resp. $h^{\prime}$ ). The choice functions of the hospitals, $C_{h}(\cdot)$ and $C_{h^{\prime}}(\cdot)$, are induced by preference profiles

$$
\begin{aligned}
& \succ_{h}:\left\{x_{1}\right\} \succ_{h}\left\{x_{2}, x_{3}\right\} \succ_{h}\left\{x_{2}\right\} \succ_{h}\left\{x_{3}\right\} \succ_{h} \varnothing, \text { and } \\
& \succ_{h^{\prime}}:\left\{x_{2}^{\prime}\right\} \succ_{h^{\prime}}\left\{x_{1}^{\prime}\right\} \succ_{h^{\prime}} \varnothing,
\end{aligned}
$$

respectively. ${ }^{15}$ Notice that the resulting choice functions satisfy the substitutes condition (Definition 1 in Appendix A) and thus, the doctor-optimal stable allocation exists for any $\succ_{D}$, as summarized in Table 1 .

To see the rural hospital theorem fails to hold in this market, fix a preference profile $\succ_{D}$ such that

$$
\begin{aligned}
& \succ_{d_{1}}: x_{1}^{\prime} \succ_{d_{1}} x_{1} \succ_{d_{1}} \varnothing, \\
& \succ_{d_{2}}: x_{2} \succ_{d_{1}} x_{2}^{\prime} \succ_{d_{1}} \varnothing, \text { and } \\
& \succ_{d_{3}}: x_{3} \succ_{d_{3}} \varnothing .
\end{aligned}
$$

As shown in the colored cell in Table 1, the doctor-optimal stable allocation at such $\succ_{D}$ is $X^{*}=\left\{x_{1}^{\prime}, x_{2}, x_{3}\right\}$, whereas there exists another stable allocation $X_{*}=\left\{x_{1}, x_{2}^{\prime}\right\}$. Note that doctor $d_{3}$ is assigned a non-null contract at $X^{*}$ but not at $X_{*}$, and hence, the rural hospital theorem fails.

To complete the proof, it remains to verify that the doctor-optimal stable rule, $X^{*}(\cdot)$, is strategy-proof in this market. For doctors $d_{1}$ and $d_{2}$, note that $\mathrm{x}\left(d_{1}, X^{*}\left(\succ_{D}\right)\right)$ and $\mathrm{x}\left(d_{2}, X^{*}\left(\succ_{D}\right)\right)$ are independent of $\succ_{d_{3}}$. Hence, the incentives for doctors $d_{1}$ and $d_{2}$ to manipulate will remain unchanged if $d_{3}$ is eliminated from the market. Actually, once $d_{3}$ is omitted, the remaining market reduces to a standard one-to-one matching mar-

\footnotetext{
${ }^{15}$ That is, for each $X^{\prime} \subset X, C_{h}\left(X^{\prime}\right)$ and $C_{h^{\prime}}\left(X^{\prime}\right)$ are the most preferred subsets of $X^{\prime} \cap X(h, X)$ and $X^{\prime} \cap$ $X\left(h^{\prime}, X\right)$ according to $\succ_{h}$ and $\succ_{h^{\prime}}$, respectively.
} 


\begin{tabular}{r|c|c|c|c|c|}
\multicolumn{1}{c}{$x_{2}, x_{2}^{\prime}, \varnothing$} & $x_{2}^{\prime}, x_{2}, \varnothing$ & $x_{2}, \varnothing$ & \multicolumn{1}{c}{$x_{2}^{\prime}, \varnothing$} & $\varnothing$ \\
\cline { 2 - 6 }$x_{1}, x_{1}^{\prime}, \varnothing$ & $\left\{x_{1}, x_{2}^{\prime}\right\}$ & $\left\{x_{1}, x_{2}^{\prime}\right\}$ & $\left\{x_{1}\right\}$ & $\left\{x_{1}, x_{2}^{\prime}\right\}$ & $\left\{x_{1}\right\}$ \\
\cline { 2 - 6 }$x_{1}^{\prime}, x_{1}, \varnothing$ & $\left\{x_{1}^{\prime}, x_{2}, x_{3}\right\}$ & $\left\{x_{1}, x_{2}^{\prime}\right\}$ & $\left\{x_{1}^{\prime}, x_{2}, x_{3}\right\}$ & $\left\{x_{1}, x_{2}^{\prime}\right\}$ & $\left\{x_{1}^{\prime}, x_{3}\right\}$ \\
\cline { 2 - 6 }$x_{1}, \varnothing$ & $\left\{x_{1}, x_{2}^{\prime}\right\}$ & $\left\{x_{1}, x_{2}^{\prime}\right\}$ & $\left\{x_{1}\right\}$ & $\left\{x_{1}, x_{2}^{\prime}\right\}$ & $\left\{x_{1}\right\}$ \\
\cline { 2 - 6 }$x_{1}^{\prime}, \varnothing$ & $\left\{x_{1}^{\prime}, x_{2}, x_{3}\right\}$ & $\left\{x_{2}^{\prime}, x_{3}\right\}$ & $\left\{x_{1}^{\prime}, x_{2}, x_{3}\right\}$ & $\left\{x_{2}^{\prime}, x_{3}\right\}$ & $\left\{x_{1}^{\prime}, x_{3}\right\}$ \\
\cline { 2 - 6 }$\varnothing$ & $\left\{x_{2}, x_{3}\right\}$ & $\left\{x_{2}^{\prime}, x_{3}\right\}$ & $\left\{x_{2}, x_{3}\right\}$ & $\left\{x_{2}^{\prime}, x_{3}\right\}$ & $\left\{x_{3}\right\}$ \\
\cline { 2 - 6 }
\end{tabular}

(a) Case of $x_{3} \in \operatorname{Ac}\left(\succ_{d_{3}}\right)$.

\begin{tabular}{r|c|c|c|c|c|}
\multicolumn{1}{r}{} & $x_{2}, x_{2}^{\prime}, \varnothing$ & $x_{2}^{\prime}, x_{2}, \varnothing$ & $x_{2}, \varnothing$ & \multicolumn{1}{c}{$x_{2}^{\prime}, \varnothing$} & $\varnothing$ \\
\cline { 2 - 6 }$x_{1}, x_{1}^{\prime}, \varnothing$ & $\left\{x_{1}, x_{2}^{\prime}\right\}$ & $\left\{x_{1}, x_{2}^{\prime}\right\}$ & $\left\{x_{1}\right\}$ & $\left\{x_{1}, x_{2}^{\prime}\right\}$ & $\left\{x_{1}\right\}$ \\
\cline { 2 - 6 }$x_{1}^{\prime}, x_{1}, \varnothing$ & $\left\{x_{1}^{\prime}, x_{2}\right\}$ & $\left\{x_{1}, x_{2}^{\prime}\right\}$ & $\left\{x_{1}^{\prime}, x_{2}\right\}$ & $\left\{x_{1}, x_{2}^{\prime}\right\}$ & $\left\{x_{1}^{\prime}\right\}$ \\
\cline { 2 - 6 }$x_{1}, \varnothing$ & $\left\{x_{1}, x_{2}^{\prime}\right\}$ & $\left\{x_{1}, x_{2}^{\prime}\right\}$ & $\left\{x_{1}\right\}$ & $\left\{x_{1}, x_{2}^{\prime}\right\}$ & $\left\{x_{1}\right\}$ \\
\cline { 2 - 6 }$x_{1}^{\prime}, \varnothing$ & $\left\{x_{1}^{\prime}, x_{2}\right\}$ & $\left\{x_{2}^{\prime}\right\}$ & $\left\{x_{1}^{\prime}, x_{2}\right\}$ & $\left\{x_{2}^{\prime}\right\}$ & $\left\{x_{1}^{\prime}\right\}$ \\
\cline { 2 - 6 }$\varnothing$ & $\left\{x_{2}\right\}$ & $\left\{x_{2}^{\prime}\right\}$ & $\left\{x_{2}\right\}$ & $\left\{x_{2}^{\prime}\right\}$ & $\varnothing$ \\
\cline { 2 - 6 } & \multicolumn{4}{c}{} & \multicolumn{3}{c}{} \\
\hline
\end{tabular}

(b) Case of $x_{3} \notin \operatorname{Ac}\left(\succ_{d_{3}}\right)$.

Table 1: Doctor optimal stable allocations in the proof of Fact 1. The rows and columns represent the preferences of doctor $d_{1}$ and $d_{2}$, respectively. ${ }^{16}$

ket without contracts and thus, $d_{1}$ and $d_{2}$ have no incentive to manipulate the doctoroptimal stable rule (Dubins and Freedman, 1981; Roth, 1982). For doctor $d_{3}$, observe that $\mathrm{x}\left(d_{3}, X^{*}\left(\succ_{D}\right)\right)$ is either $x_{3}$ or $\varnothing$, and that it depends on $\succ_{d_{3}}$ only through whether or not $x_{3} \in \operatorname{Ac}\left(\succ_{d_{3}}\right)$. Therefore, $d_{3}$ has no incentive to report that $x_{3}$ is acceptable when it is not, and vice versa. In sum, the doctor-optimal stable rule is strategy-proof in this market, and the proof is complete.

\footnotetext{
${ }^{16}$ Here we abuse notation and identify preferences with ordered lists (up to the null contract). For instance, " $x_{1}, x_{1}^{\prime}, \varnothing$ " represents $\succ_{d_{1}}$ such that $x_{1} \succ_{d_{1}} x_{1}^{\prime} \succ_{d_{1}} \varnothing$. The same applies to all tables below.
} 
Another natural question that stems from Theorem 2 would be whether or not the necessary condition for a stable and strategy-proof rule can be replaced with a weaker notion of optimality. Specifically, one might wonder if a stable and strategy-proof rule always chooses an allocation that is not dominated by another stable allocation. Actually, the answer to this question is known to be negative. ${ }^{17}$

Fact 2 (Kominers and Sönmez, 2014). A stable and strategy-proof rule may choose an allocation that is strictly dominated by another stable allocation.

Proof. In the case of slot-specific priorities, Kominers and Sönmez (2014) show that the cumulative offer process may not choose the doctor-optimal stable allocation even when it exists (Example 4), whereas it always induces a stable and strategy-proof rule (Theorem $4)$.

Given that the outcomes of a stable and strategy-proof rule may be dominated even among the stable allocations, it could be of policy interest whether the doctor welfare can be Pareto-improved. Since Theorem 1 implies that such improvement is impossible maintaining both stability and strategy-proofness, it would be natural to ask if it becomes possible once we weaken the stability requirement. Our last main result, Theorem 3, shows that such improvement is generally impossible. This extends the existing results in the school choice literature that the student-optimal stable rule is second-best optimal among strategy-proof rules (see, Abdulkadiroglu et al., 2009; Kesten, 2010; Kesten and Kurino, 2013). ${ }^{18}$

Theorem 3. Suppose that every hospital $h$ has a choice function $C_{h}(\cdot)$ satisfying the IRC condition. Then, no individually-rational and strategy-proof rule strictly dominates a stable and strategy-proof rule.

\footnotetext{
${ }^{17}$ In matching markets without contracts, contrastingly, Pathak and Sönmez (2013, Lemma 1) establish that the dominance in terms of outcomes between two stable rules implies the dominance in terms of manipulability. For an extension of this result, see also Chen et al. (2014).

${ }^{18}$ See also Anno and Kurino (2014) and Erdil (2014) for related results.
} 
Proof. Towards a contradiction, suppose that $f(\cdot)$ is individually rational and strategyproof, $g(\cdot)$ is stable and strategy-proof, and that $f(\cdot)$ strictly dominates $g(\cdot)$. Let $\succ_{D}^{*} \in$ $\mathscr{P}_{D}$ be a preference profile such that $f\left(\succ_{D}^{*}\right) \neq g\left(\succ_{D}^{*}\right)$ and

$$
\left[f\left(\succ_{D}\right) \neq g\left(\succ_{D}\right) \Longrightarrow \sum_{d \in D}\left|\operatorname{Ac}\left(\succ_{d}\right)\right| \geq \sum_{d \in D}\left|\operatorname{Ac}\left(\succ_{d}^{*}\right)\right|\right] \text { for all } \succ_{D} \in \mathscr{P}_{D}
$$

which exists by assumption. Then, there must exist $d^{*} \in D$ such that

$$
\mathrm{x}\left(d^{*}, f\left(\succ_{D}^{*}\right)\right) \succ_{d^{*}}^{*} \mathrm{x}\left(d^{*}, g\left(\succ_{D}^{*}\right)\right) \succ_{d^{*}}^{*} \varnothing
$$

To see this, suppose contrarily that for all $d \in D, \mathrm{x}\left(d, f\left(\succ_{D}^{*}\right)\right) \succ_{d}^{*} \times\left(d, g\left(\succ_{D}^{*}\right)\right)$ implies $\mathrm{x}\left(d, g\left(\succ_{D}^{*}\right)\right)=\varnothing$. This requires $f\left(\succ_{D}^{*}\right) \supsetneq g\left(\succ_{D}^{*}\right)$ and hence, for some $h \in H$,

$$
\begin{aligned}
C_{h}\left(f\left(\succ_{D}^{*}\right) \cup g\left(\succ_{D}^{*}\right)\right)=C_{h}\left(f\left(\succ_{D}^{*}\right)\right) & =\mathrm{X}\left(h, f\left(\succ_{D}^{*}\right)\right) \\
& \neq \mathrm{X}\left(h, g\left(\succ_{D}^{*}\right)\right)=C_{h}\left(g\left(\succ_{D}^{*}\right)\right),
\end{aligned}
$$

where the second and last equalities hold by the individual rationality of $f(\cdot)$ and $g(\cdot)$, respectively. Therefore, $\left(h, f\left(\succ_{D}^{*}\right)\right)$ weakly blocks $g\left(\succ_{D}^{*}\right)$, but by Lemma 1 , this contradicts the stability of $g(\cdot)$.

Now, take a new preference relation $\succ_{d^{*}}^{* *}$ of $d^{*}$ such that $\operatorname{Ac}\left(\succ_{d^{*}}^{* *}\right)=\left\{\mathrm{x}\left(d^{*}, f\left(\succ_{D}^{*}\right)\right)\right\}$, and let $\succ_{D}^{* *}=\left(\succ_{d^{*}}^{* *} \succ_{D-\left\{d^{*}\right\}}^{*}\right)$. Then, the strategy-proofness of $f(\cdot)$ and $g(\cdot)$ implies

$$
\mathrm{x}\left(d^{*}, f\left(\succ_{D}^{* *}\right)\right)=\mathrm{x}\left(d^{*}, f\left(\succ_{D}^{*}\right)\right) \succ_{d^{*}}^{*} \mathrm{x}\left(d^{*}, g\left(\succ_{D}^{*}\right)\right) \succ_{d^{*}}^{*} \mathrm{x}\left(d^{*}, g\left(\succ_{D}^{* *}\right)\right)=\varnothing,
$$

and thus, $f\left(\succ_{D}^{* *}\right) \neq g\left(\succ_{D}^{* *}\right)$. However, this contradicts the definition of $\succ_{D}^{*}$ since $\left|\operatorname{Ac}\left(\succ_{d^{*}}^{* *}\right)\right|<\left|\operatorname{Ac}\left(\succ_{d^{*}}^{*}\right)\right|$ and $\succ_{D-\left\{d^{*}\right\}}^{* *}=\succ_{D-\left\{d^{*}\right\}^{\prime}}^{*}$ and the proof is complete.

In Appendix B, we provide two variants of this theorem. First, we show that the same 
claim holds even if stability is weaken to non-wastefulness (Theorem 4), taking $C_{h}\left(X^{\prime}\right)=$ $\mathrm{X}\left(h, X^{\prime}\right)$ as the feasibility constraint, and this result is further generalized to accommodate tie-breaking (Corollary 3). Second, we also show that the stable and strategy-proof rule in the above statement can be replaced with the doctor-optimal stable rule. That is, if the doctor-optimal stable rule is not strategy-proof, two possible policy goals, to achieve strategy-proofness and to unambiguously improve doctor welfare (by relaxing stability requirement), are incompatible with each other.

\section{Concluding Remarks}

This paper studies the model of many-to-one matching with contracts, and derives a number of properties that a stable and strategy-proof rule must generally satisfy. A notable feature of our approach is that we only impose a minimal structure on hospitals' choice functions, i.e., the IRC condition, and do not rely on any algorithmic properties of a matching rule. This generality allows us to capture the joint implications of stability and strategy-proofness in a transparent way. Yet, a cost of our abstract approach is that it cannot tell much about when a stable and strategy-proof rule exists and how to find such a rule if it exists (and is not the doctor-optimal stable rule). In this regard, a closely related but independent paper by Hatfield et al. (2015) identifies a sufficient condition and an almost necessary condition for the cumulative offer process to be stable and strategy-proof. To highlight the distinction between the scope of the two studies, we provide an example of a stable and strategy-proof rule that is not induced by the cumulative offer process (or the deferred acceptance algorithm). ${ }^{19}$

\footnotetext{
${ }^{19}$ In the following example, the doctor-optimal stable rule does not exist. Example 2 in Appendix C presents a market where the doctor-optimal stable rule exists, is strategy-proof, but is not induced by the cumulative offer process.
} 
Fact 3. There can exist a stable and strategy-proof rule that is not induced by the cumulative offer process. $^{20}$

Proof. The proof is by example. Let $D=\left\{d_{1}, d_{2}, d_{3}\right\}, H=\{h\}$, and $X=\left\{x_{i}, y_{i}\right\}_{i \in\{1,2,3\}}$, where $x_{i}$ and $y_{i}$ denote two distinct contracts between $d_{i}$ and $h$. The hospital's choice function is induced by

$$
\begin{aligned}
\succ_{h}:\left\{x_{1}, y_{2}, y_{3}\right\} \succ_{h}\left\{y_{1}, x_{2}, y_{3}\right\} & \succ_{h}\left\{x_{1}, x_{2}, y_{3}\right\} \\
& \succ_{h}\left\{y_{1}, y_{2}\right\} \succ_{h}\left\{y_{1}\right\} \succ_{h}\left\{y_{2}\right\} \succ_{h}\left\{x_{3}\right\} \succ_{h} \varnothing .
\end{aligned}
$$

Given the resulting choice function $C_{h}(\cdot)$, define a stable rule $f(\cdot)$ as in Tables $2-3$. In what follows, we will show that this $f(\cdot)$ is strategy-proof but not induced by the cumulative offer process.

First, we verify the strategy-proofness of $f(\cdot)$. By checking each column of Tables 2-3 we can make the following observation: Taking $\succ_{d_{2}}$ and $\succ_{d_{3}}$ as fixed, doctor $d_{1}$ is always assigned his best contracts either from $\left\{x_{1}, y_{1}, \varnothing\right\}$ or from $\left\{y_{1}, \varnothing\right\}$. In either case, as his "choice set" is independent of $\succ_{d_{1}}$, it is apparent that doctor $d_{1}$ has no incentive to misreport. Similarly, we can see, by checking the rows of Tables $2-3$, that doctor $d_{2}$ cannot profitably manipulate $f(\cdot)$. Further, although it is more cumbersome, we can also confirm that doctor $d_{3}$ is assigned his best contract (i) from $\left\{x_{3}, y_{3}, \varnothing\right\}$ when $\operatorname{Ac}\left(\succ_{d_{1}}\right) \cup \operatorname{Ac}\left(\succ_{d_{2}}\right)=$ $\left\{x_{1}, x_{2}\right\}$, (ii) from $\left\{x_{3}, \varnothing\right\}$ when $\operatorname{Ac}\left(\succ_{d_{1}}\right) \cup \operatorname{Ac}\left(\succ_{d_{2}}\right)=\varnothing,\left\{x_{1}\right\}$, or $\left\{x_{2}\right\}$, (iii) from $\{\varnothing\}$ when $\operatorname{Ac}\left(\succ_{d_{1}}\right) \cup \operatorname{Ac}\left(\succ_{d_{2}}\right)=\left\{x_{1}, y_{1}\right\}$ or $\left\{x_{2}, y_{2}\right\}$, and (iv) from $\left\{y_{3}, \varnothing\right\}$ otherwise; thus, $f(\cdot)$ is also strategy-proof for doctor $d_{3}$.

To show that $f(\cdot)$ is not induced by the cumulative offer process, suppose that $\succ_{D}$ is

\footnotetext{
${ }^{20}$ More precisely, what we illustrate below is a stable and strategy-proof rule that is not induced by any (either single-offer or simultaneous-offer) cumulative offer process, even though we can define multiple (order-dependent) cumulative offer processes. See also footnote 23 in Appendix A.
} 


\begin{tabular}{|c|c|c|c|c|c|}
\hline & $x_{2}, y_{2}, \varnothing$ & $y_{2}, x_{2}, \varnothing$ & $x_{2}, \varnothing$ & $y_{2}, \varnothing$ & $\varnothing$ \\
\hline$x_{1}, y_{1}, \varnothing$ & $\left\{x_{1}, x_{2}, y_{3}\right\}$ & $\left\{x_{1}, y_{2}, y_{3}\right\}$ & $\left\{y_{1}, x_{2}, y_{3}\right\}$ & $\left\{x_{1}, y_{2}, y_{3}\right\}$ & $\left\{y_{1}\right\}$ \\
\hline$y_{1}, x_{1}, \varnothing$ & $\left\{y_{1}, x_{2}, y_{3}\right\}$ & $\left\{y_{1}, y_{2}\right\}$ & $\left\{y_{1}, x_{2}, y_{3}\right\}$ & $\left\{y_{1}, y_{2}\right\}$ & $\left\{y_{1}\right\}$ \\
\hline$x_{1}, \varnothing$ & $\left\{x_{1}, y_{2}, y_{3}\right\}$ & $\left\{x_{1}, y_{2}, y_{3}\right\}$ & $\left\{x_{3}\right\}$ & $\left\{x_{1}, y_{2}, y_{3}\right\}$ & $\left\{x_{3}\right\}$ \\
\hline$y_{1}, \varnothing$ & $\left\{y_{1}, x_{2}, y_{3}\right\}$ & $\left\{y_{1}, y_{2}\right\}$ & $\left\{y_{1}, x_{2}, y_{3}\right\}$ & $\left\{y_{1}, y_{2}\right\}$ & $\left\{y_{1}\right\}$ \\
\hline$\varnothing$ & $\left\{y_{2}\right\}$ & $\left\{y_{2}\right\}$ & $\left\{x_{3}\right\}$ & $\left\{y_{2}\right\}$ & $\left\{x_{3}\right\}$ \\
\hline
\end{tabular}

(a) Case of $x_{3} \succ_{d_{3}} y_{3} \succ_{d_{3}} \varnothing$.

\begin{tabular}{|c|c|c|c|c|c|}
\hline & $x_{2}, y_{2}, \varnothing$ & $y_{2}, x_{2}, \varnothing$ & $x_{2}, \varnothing$ & $y_{2}, \varnothing$ & $\varnothing$ \\
\hline$x_{1}, y_{1}, \varnothing$ & $\left\{x_{1}, x_{2}, y_{3}\right\}$ & $\left\{x_{1}, y_{2}, y_{3}\right\}$ & $\left\{x_{1}, x_{2}, y_{3}\right\}$ & $\left\{x_{1}, y_{2}, y_{3}\right\}$ & $\left\{y_{1}\right\}$ \\
\hline$y_{1}, x_{1}, \varnothing$ & $\left\{y_{1}, x_{2}, y_{3}\right\}$ & $\left\{y_{1}, y_{2}\right\}$ & $\left\{y_{1}, x_{2}, y_{3}\right\}$ & $\left\{y_{1}, y_{2}\right\}$ & $\left\{y_{1}\right\}$ \\
\hline$x_{1}, \varnothing$ & $\left\{x_{1}, x_{2}, y_{3}\right\}$ & $\left\{x_{1}, y_{2}, y_{3}\right\}$ & $\left\{x_{1}, x_{2}, y_{3}\right\}$ & $\left\{x_{1}, y_{2}, y_{3}\right\}$ & $\left\{x_{3}\right\}$ \\
\hline$y_{1}, \varnothing$ & $\left\{y_{1}, x_{2}, y_{3}\right\}$ & $\left\{y_{1}, y_{2}\right\}$ & $\left\{y_{1}, x_{2}, y_{3}\right\}$ & $\left\{y_{1}, y_{2}\right\}$ & $\left\{y_{1}\right\}$ \\
\hline$\varnothing$ & $\left\{y_{2}\right\}$ & $\left\{y_{2}\right\}$ & $\left\{x_{3}\right\}$ & $\left\{y_{2}\right\}$ & $\left\{x_{3}\right\}$ \\
\hline
\end{tabular}

(b) Case of $y_{3} \succ_{d_{3}} x_{3} \succ_{d_{3}} \varnothing$.

\begin{tabular}{|c|c|c|c|c|c|}
\hline & $x_{2}, y_{2}, \varnothing$ & $y_{2}, x_{2}, \varnothing$ & $x_{2}, \varnothing$ & $y_{2}, \varnothing$ & $\varnothing$ \\
\hline$x_{1}, y_{1}, \varnothing$ & $\left\{x_{1}, x_{2}, y_{3}\right\}$ & $\left\{x_{1}, y_{2}, y_{3}\right\}$ & $\left\{x_{1}, x_{2}, y_{3}\right\}$ & $\left\{x_{1}, y_{2}, y_{3}\right\}$ & $\left\{y_{1}\right\}$ \\
\hline$y_{1}, x_{1}, \varnothing$ & $\left\{y_{1}, x_{2}, y_{3}\right\}$ & $\left\{y_{1}, y_{2}\right\}$ & $\left\{y_{1}, x_{2}, y_{3}\right\}$ & $\left\{y_{1}, y_{2}\right\}$ & $\left\{y_{1}\right\}$ \\
\hline$x_{1}, \varnothing$ & $\left\{x_{1}, x_{2}, y_{3}\right\}$ & $\left\{x_{1}, y_{2}, y_{3}\right\}$ & $\left\{x_{1}, x_{2}, y_{3}\right\}$ & $\left\{x_{1}, y_{2}, y_{3}\right\}$ & $\varnothing$ \\
\hline$y_{1}, \varnothing$ & $\left\{y_{1}, x_{2}, y_{3}\right\}$ & $\left\{y_{1}, y_{2}\right\}$ & $\left\{y_{1}, x_{2}, y_{3}\right\}$ & $\left\{y_{1}, y_{2}\right\}$ & $\left\{y_{1}\right\}$ \\
\hline$\varnothing$ & $\left\{y_{2}\right\}$ & $\left\{y_{2}\right\}$ & $\varnothing$ & $\left\{y_{2}\right\}$ & $\varnothing$ \\
\hline
\end{tabular}

(c) Case of $y_{3} \succ_{d_{3}} \varnothing \succ_{d_{3}} x_{3}$.

Table 2: Definition of $f(\cdot)$ in the proof of Fact 3. The rows and columns represent the preferences of doctor $d_{1}$ and $d_{2}$, respectively. 


\begin{tabular}{|c|c|c|c|c|c|}
\hline & $x_{2}, y_{2}, \varnothing$ & $y_{2}, x_{2}, \varnothing$ & $x_{2}, \varnothing$ & $y_{2}, \varnothing$ & $\varnothing$ \\
\hline$x_{1}, y_{1}, \varnothing$ & $\left\{y_{1}, y_{2}\right\}$ & $\left\{y_{1}, y_{2}\right\}$ & $\left\{y_{1}\right\}$ & $\left\{y_{1}, y_{2}\right\}$ & $\left\{y_{1}\right\}$ \\
\hline$y_{1}, x_{1}, \varnothing$ & $\left\{y_{1}, y_{2}\right\}$ & $\left\{y_{1}, y_{2}\right\}$ & $\left\{y_{1}\right\}$ & $\left\{y_{1}, y_{2}\right\}$ & $\left\{y_{1}\right\}$ \\
\hline$x_{1}, \varnothing$ & $\left\{y_{2}\right\}$ & $\left\{y_{2}\right\}$ & $\left\{x_{3}\right\}$ & $\left\{y_{2}\right\}$ & $\left\{x_{3}\right\}$ \\
\hline$y_{1}, \varnothing$ & $\left\{y_{1}, y_{2}\right\}$ & $\left\{y_{1}, y_{2}\right\}$ & $\left\{y_{1}\right\}$ & $\left\{y_{1}, y_{2}\right\}$ & $\left\{y_{1}\right\}$ \\
\hline$\varnothing$ & $\left\{y_{2}\right\}$ & $\left\{y_{2}\right\}$ & $\left\{x_{3}\right\}$ & $\left\{y_{2}\right\}$ & $\left\{x_{3}\right\}$ \\
\hline
\end{tabular}

(a) Case of $x_{3} \succ_{d_{3}} \varnothing \succ_{d_{3}} y_{3}$.

\begin{tabular}{r|c|c|c|c|c|}
\multicolumn{1}{r}{} & \multicolumn{1}{c}{$x_{2}, y_{2}, \varnothing$} & $y_{2}, x_{2}, \varnothing$ & $x_{2}, \varnothing$ & $y_{2}, \varnothing$ & $\varnothing$ \\
\cline { 2 - 6 }$x_{1}, y_{1}, \varnothing$ & $\left\{y_{1}, y_{2}\right\}$ & $\left\{y_{1}, y_{2}\right\}$ & $\left\{y_{1}\right\}$ & $\left\{y_{1}, y_{2}\right\}$ & $\left\{y_{1}\right\}$ \\
\cline { 2 - 6 }$y_{1}, x_{1}, \varnothing$ & $\left\{y_{1}, y_{2}\right\}$ & $\left\{y_{1}, y_{2}\right\}$ & $\left\{y_{1}\right\}$ & $\left\{y_{1}, y_{2}\right\}$ & $\left\{y_{1}\right\}$ \\
\cline { 2 - 6 }$x_{1}, \varnothing$ & $\left\{y_{2}\right\}$ & $\left\{y_{2}\right\}$ & $\varnothing$ & $\left\{y_{2}\right\}$ & $\varnothing$ \\
\cline { 2 - 6 }$y_{1}, \varnothing$ & $\left\{y_{1}, y_{2}\right\}$ & $\left\{y_{1}, y_{2}\right\}$ & $\left\{y_{1}\right\}$ & $\left\{y_{1}, y_{2}\right\}$ & $\left\{y_{1}\right\}$ \\
\cline { 2 - 6 }$\varnothing$ & $\left\{y_{2}\right\}$ & $\left\{y_{2}\right\}$ & $\varnothing$ & $\left\{y_{2}\right\}$ & $\varnothing$ \\
\cline { 2 - 6 }
\end{tabular}

(b) Case of $\operatorname{Ac}\left(\succ_{d_{3}}\right)=\varnothing$.

Table 3: Definition of $f(\cdot)$ in in the proof of Fact 3 (continued). The rows and columns represent the preferences of doctor $d_{1}$ and $d_{2}$, respectively.

given by

$$
\begin{aligned}
& \succ_{d_{1}}: x_{1} \succ_{d_{1}} y_{1} \succ_{d_{1}} \varnothing, \\
& \succ_{d_{2}}: x_{2} \succ_{d_{2}} y_{2} \succ_{d_{2}} \varnothing, \text { and } \\
& \succ_{d_{3}}: x_{3} \succ_{d_{3}} y_{3} \succ_{d_{3}} \varnothing .
\end{aligned}
$$

With this preference profile, $f\left(\succ_{D}\right)=\left\{x_{1}, x_{2}, y_{3}\right\}$, as specified in the colored cell in Table 
2a. For the cumulative offer process to return this outcome, doctor $d_{3}$ needs to propose $y_{3}$ and hence, $x_{3}$ must be rejected beforehand. This further implies that $y_{1}$ or $y_{2}$ (or both) must be offered by the end of the process. Then, however, the final pool of offers must contain $\left\{x_{1}, y_{2}, y_{3}\right\}$ or $\left\{y_{1}, x_{2}, y_{3}\right\}$ (or both) and thus, the hospital must not pick $f\left(\succ_{D}\right)=$ $\left\{x_{1}, x_{2}, y_{3}\right\}$, which is less preferable. That is, the stable and strategy-proof rule $f(\cdot)$ is not induced by the cumulative offer process in this market.

It is also worth mentioning that all of our proofs share a common technique to derive a contradiction starting from a "minimal" preference profile in terms of the number of acceptable contracts. While this technique could be also useful elsewhere, it should be noted that it necessitates the existence of a null-contract as well as the full preference domain. Consequently, our results do not directly extend to an environment where the null-contract does not exist or the preference domain is restricted, e.g., as in Kesten (2010) and Kesten and Kurino (2013).

\section{Acknowledgment}

We thank Fuhito Kojima and participants at the 15th SAET conference for helpful comments and suggestions.

\section{A Additional Definitions}

This section provides the definitions of several existing concepts that are referred to but not defined in the main text. To begin, the following substitutes conditions, introduced by Hatfield and Milgrom (2005) and Hatfield and Kojima (2010), play a central role in the matching with contracts literature. ${ }^{21}$

\footnotetext{
${ }^{21}$ See also Afacan and Turhan (2015) for the relationships among these conditions.
} 
Definition 1. Hospital $h$ 's choice function satisfies the substitutes condition if there do not exist contacts $x$ and subsets $X^{\prime}, X^{\prime \prime} \subset X$ of contracts such that (i) $x \notin C_{h}\left(X^{\prime} \cup\{x\}\right)$ and (ii) $x \in C_{h}\left(X^{\prime} \cup X^{\prime \prime} \cup\{x\}\right)$.

Definition 2. Hospital $h$ 's choice function $C_{h}(\cdot)$ satisfies the unilateral substitutes condition if there do not exist contracts $x, y \in X$ and a subset $X^{\prime} \subset X$ of contracts such that (i) $\mathrm{d}(x) \notin\left\{\mathrm{d}\left(x^{\prime}\right)\right\}_{x^{\prime} \in X^{\prime}}$, (ii) $x \notin C_{h}\left(X^{\prime} \cup\{x\}\right)$, and (iii) $x \in C_{h}\left(X^{\prime} \cup\{x, y\}\right)$.

Definition 3. Hospital $h^{\prime}$ s choice function $C_{h}(\cdot)$ satisfies the bilateral substitutes condition if there do not exist contracts $x, y \in X$ and a subset $X^{\prime} \subset X$ of contracts such that (i) $\mathrm{d}(x), \mathrm{d}(y) \notin\left\{\mathrm{d}\left(x^{\prime}\right)\right\}_{x^{\prime} \in X^{\prime}}$, (ii) $x \notin C_{h}\left(X^{\prime} \cup\{x\}\right)$, and (iii) $x \in C_{h}\left(X^{\prime} \cup\{x, y\}\right)$.

Hatfield and Milgrom (2005) also introduce the following condition.

Definition 4. Hospital $h$ 's choice function $C_{h}(\cdot)$ satisfies the law of aggregated demand if $X^{\prime} \subset X^{\prime \prime}$ implies $\left|C_{h}\left(X^{\prime}\right)\right| \leq\left|C_{h}\left(X^{\prime \prime}\right)\right|$ for all $X^{\prime}, X^{\prime \prime} \subset X$.

Kominers and Sönmez $(2013,2014)$ study the markets where the hospitals' choice functions are induced by slot-specific priorities. They show that such choice functions may violate the unilateral substitutes condition, but always satisfy the bilateral substitutes condition.

Definition 5. A collection $\left(\succ_{h, s}\right)_{1 \leq s \leq q_{h}}$ of linear orders, called slot-specific priorities, over $\{x \in X: \mathrm{h}(x)=h\} \cup\{\varnothing\}$ induces a choice function for hospital $h$ as follows: For each $X^{\prime} \subset X, C_{h}\left(X^{\prime}\right)=\left\{x_{1}, \ldots, x_{q_{h}}\right\}-\{\varnothing\}$, where $x_{s}$ is recursively defined by letting

- $X_{s}^{\prime}=X_{s-1}^{\prime}-\left\{x \in X_{s-1}^{\prime}: \mathrm{d}(x)=\mathrm{d}\left(x_{s-1}\right)\right\}$, where $X_{0}^{\prime}$ and $x_{0}$ are defined to be $X^{\prime}$ and $\varnothing$, and,

- $x_{s}$ be the maximal element in $X_{s}^{\prime} \cup\{\varnothing\}$, with respect to $\succ_{h, s}$

for each $s=1, \ldots, q_{h}$. 
Hatfield and Kojima (2010) show that the cumulative offer process, originally defined by Hatfield and Milgrom (2005), can find a stable allocation whenever the bilateral substitutes condition is satisfied, under which the deferred acceptance algorithm may fail to do so. ${ }^{22} 23$

Definition 6. Given $\left(C_{H}(\cdot), \succ_{D}\right)$, the cumulative offer process proceeds as follows.

- Initial condition: Let $D_{0}=D$ and $P_{0}=\varnothing$.

- Step $t \geq 1$ : Each $d \in D_{t-1}$ offers her best contract, $x_{t}^{d}$, among those remaining (i.e., among $\left.X \backslash P_{t-1}\right)$. Let $P_{t}=P_{t-1} \cup\left\{x_{t}^{d}\right\}_{d \in D_{t-1}}$ be the pool of contracts that have been offered up to this step. Among $P_{t}$, each hospital $h$ holds the best combination of contracts, $C_{h}\left(P_{t}\right)$. Finally, let $D_{t}$ be the set of doctors for whom (i) no contract is currently held by any hospital and (ii) not all acceptable contracts have been offered yet, i.e.,

$$
D_{t}=\left\{d \in D: d \notin\left[C_{h}\left(P_{t}\right)\right]_{D} \text { for all } h \in H \text { and } \operatorname{Ac}\left(\succ_{d}\right) \backslash P_{t} \neq \varnothing\right\} .
$$

Proceed to step $t+1$ if $D_{t}$ is non-empty and terminate otherwise.

- Outcome: When the process terminates at step $T$, its outcome is $\bigcup_{h \in H} C_{h}\left(P_{T}\right)$.

\footnotetext{
${ }^{22}$ For further properties of the cumulative offer process, see also Afacan (2014).

${ }^{23}$ The following definition is equivalent to the one by Hatfield and Milgrom (2005) and is referred to as the simultaneous-offer cumulative offer process in Hirata and Kasuya (2014). In the literature, it is also common to define the class of single-offer processes, where only a single doctor makes an offer at each step of the algorithm. Those definitions are not equivalent in general, although they are under certain conditions (Hatfield and Kominers, 2014; Hatfield et al., 2015; Hirata and Kasuya, 2014; Kominers and Sönmez, 2013, 2014).
} 


\section{B Additional Results}

This section provides two variants of Theorem 3 in the main text. First, we show that stability in Theorem 3 can be replaced with the following weaker requirement: An individually rational allocation $X^{\prime}$ is said to be non-wasteful if there is no other individually rational allocation $X^{\prime \prime}$ with $X^{\prime \prime} \supsetneq X^{\prime} .{ }^{24}$ If we take $C_{h}\left(X^{\prime}\right)=X\left(h, X^{\prime}\right)$ as a feasibility constraint, this condition roughly says no hospital can accommodate any unmatched doctors without crowding out other (already matched) doctors. It reduces to the standard definition in assignment problems, if we endow each hospital (or object) $h$ with $C_{h}(\cdot)$ such that $C_{h}\left(X^{\prime}\right)=X\left(h, X^{\prime}\right)$ if and only if $\left|X\left(h, X^{\prime}\right)\right| \leq q_{h}$, where $q_{h}$ is the "quota" of $h{ }^{25}$ In addition, the current matching-with-contracts setup allows a richer class of constraints that could be of practical relevance. For example, suppose that a school offers two distinct programs, and they require some common resources at different factor intensity (e.g., one is mathematics-teacher intensive while the other is English-teacher intensive). Then, the total number of students that those programs can accommodate would be non-constant and depend on its composition.

Theorem 4. Suppose that every hospital $h \in H$ has a choice function $C_{h}(\cdot)$ satisfying the IRC condition. Then, no individually-rational and strategy-proof rule strictly dominates a nonwasteful and strategy-proof rule.

Proof. In the proof of Theorem 3, the stability of $g(\cdot)$ is needed only to guarantee the existence of $d^{*}$ satisfying $(*)$. Hence it suffices to prove this part from non-wastefulness. Indeed, if $\mathrm{x}\left(d, f\left(\succ_{D}^{*}\right)\right) \succ_{d} \times\left(d, g\left(\succ_{D}^{*}\right)\right)$ implies $\times\left(d, g\left(\succ_{D}^{*}\right)\right)=\varnothing$ for all $d \in D$, it follows that $f\left(\succ_{D}^{*}\right) \supsetneq g\left(\succ_{D}^{*}\right)$, which directly contradicts non-wastefulness.

\footnotetext{
${ }^{24}$ It is immediate to verify that under the IRC condition, stability implies non-wastefulness as defined above. This is not the case in general; see Example 3 in Appendix $C$.

${ }^{25}$ Of course, the feasibility constraint does not uniquely pin down $C_{H}(\cdot)$, because it imposes no restriction on $C_{h}\left(X^{\prime}\right)$ when $X\left(h, X^{\prime}\right)$ is infeasible. However, this additional degree of freedom is irrelevant for the current purpose (see Corollary 3 below).
} 
Actually, this theorem can be slightly more generalized (Corollary 3), since the choice functions are relevant for individual rationality and non-wastefulness only through whether $C_{h}\left(X^{\prime}\right)=\mathrm{X}\left(h, X^{\prime}\right)$ or not. Although it is technically straightforward, this extension allows us to incorporate weak preferences of the hospital side and consequently, includes Theorem 1 of Abdulkadiroglu et al. (2009) as a special case (Corollary 4).

Corollary 3. Suppose that $C_{H}(\cdot)$ and $C_{H}^{\prime}(\cdot)$ are two profiles of choice functions satisfying the IRC condition such that $C_{h}\left(X^{\prime}\right)=X\left(h, X^{\prime}\right) \Rightarrow C_{h}^{\prime}\left(X^{\prime}\right)=X\left(h, X^{\prime}\right)$ for all $h \in H$ and $X^{\prime} \subset X$. Then, no strategy-proof rule that is individually rational with respect to $C_{H}(\cdot)$ strictly dominates a strategy-proof rule that is non-wasteful with respect to $C_{H}^{\prime}(\cdot)$.

Proof. The proof is exactly the same as of Theorems $3-4$ and thus omitted.

Corollary 4 (Abdulkadiroglu et al., 2009, Theorem 1). In the school choice problem with weak priorities, any rule induced by the deferred acceptance algorithm after tie-breaking cannot be strictly dominated by any individually-rational and strategy-proof rule.

Proof. In the school choice problem, $C_{h}\left(X^{\prime}\right)=X\left(h, X^{\prime}\right)$ holds only when the number of (acceptable) students is no more than the quota of $h$, or equivalently, only when no tiebreaking is necessary. Therefore, the condition in Corollary 3 is satisfied across different tie-breaking rules, and the claim follows from the fact that the outcome of the deferred acceptance is always non-wasteful.

Second, we can show the second-best optimality of the doctor-optimal stable rule, given its existence, no matter whether it is strategy-proof or not.

Theorem 5. Suppose that every hospital $h \in H$ has a choice function $C_{h}(\cdot)$ satisfying the IRC condition. Then, no individually-rational and strategy-proof rule strictly dominates the doctoroptimal stable rule (whether strategy-proof or not). 
Proof. Towards a contradiction, suppose that $f(\cdot)$ is individually rational and strategyproof, the doctor-optimal stable rule $X^{*}(\cdot)$ is well-defined, and that $f(\cdot)$ strictly dominates $X^{*}(\cdot)$. Let $\succ_{D}^{*} \in \mathscr{P}$ be a preference profile such that $f\left(\succ_{D}^{*}\right) \neq X^{*}\left(\succ_{D}^{*}\right)$ and

$$
\left[f\left(\succ_{D}\right) \neq X^{*}\left(\succ_{D}\right) \Longrightarrow \sum_{d \in D}\left|\operatorname{Ac}\left(\succ_{d}\right)\right| \geq \sum_{d \in D}\left|\operatorname{Ac}\left(\succ_{d}^{*}\right)\right|\right] \text { for all } \succ_{D} \in \mathscr{P}_{D},
$$

which exists by assumption. Then, for the same reasoning as in the proof of Theorem 3 , it follows from the stability of $X^{*}(\cdot)$ that there exists $d^{*} \in D$ with $\times\left(d^{*}, f\left(\succ_{D}^{*}\right)\right) \succ_{d^{*}}^{*}$ $\mathrm{x}\left(d^{*}, X^{*}\left(\succ_{D}^{*}\right)\right) \succ_{d^{*}}^{*} \varnothing$.

Now, let $\succ_{D}^{* *}=\left(\succ_{d^{*}}^{* *} \succ_{D-\left\{d^{*}\right\}}^{*}\right)$, where $\succ_{d^{*}}^{* *}$ is a truncation of $\succ_{d^{*}}^{*}$ abovex $\left(d^{*}, X^{*}\left(\succ_{D}^{*}\right)\right)$, i.e., a preference such that

$$
\operatorname{Ac}\left(\succ_{d^{*}}^{* *}\right)=\left\{x \in X: x \succ_{d^{*}}^{*} \mathrm{x}\left(d^{*}, X^{*}\left(\succ_{D}^{*}\right)\right)\right\}
$$

and

$$
\left[x \succ_{d_{*}}^{* *} y \Longleftrightarrow x \succ_{d_{*}^{*}}^{* *} y\right] \text { for all } x, y \in \operatorname{Ac}\left(\succ_{d^{*}}^{* *}\right)
$$

On the one hand, the strategy-proofness of $f(\cdot)$ implies

$$
\mathrm{x}\left(d^{*}, f\left(\succ_{D}^{* *}\right)\right)=\mathrm{x}\left(d^{*}, f\left(\succ_{D}^{*}\right)\right) \neq \varnothing
$$

On the other hand, $\mathrm{x}\left(d^{*}, X^{*}\left(\succ_{D}^{* *}\right)\right)=\varnothing$ must also hold by doctor-optimality. ${ }^{26}$ These together imply $f\left(\succ_{D}^{* *}\right) \neq g\left(\succ_{D}^{* *}\right)$, which contradicts the definition of $\succ_{D}^{*}$, and the proof is complete.

\footnotetext{
${ }^{26}$ If $\mathrm{x}\left(d^{*}, X^{*}\left(\succ_{D}^{* *}\right)\right) \neq \varnothing$, by construction, any $\left(h, X^{\prime \prime}\right)$ that blocks $X^{*}\left(\succ_{D}^{* *}\right)$ at $\succ_{D}^{*}$ must also block $X^{*}\left(\succ_{D}^{* *}\right)$ at $\succ_{D}^{* *}$. Thus $X^{*}\left(\succ_{D}^{* *}\right)$ is stable at $\succ_{D^{*}}^{*}$, but this contradicts the doctor-optimality of $X^{*}\left(\succ_{D}^{*}\right)$ for $\mathrm{x}\left(d^{*}, X^{*}\left(\succ_{D}^{* *}\right)\right) \succ_{d^{*}} \mathrm{x}\left(d^{*}, X^{*}\left(\succ_{D}^{*}\right)\right)$.
} 


\section{Examples}

This section provides the examples that are referred to in the main body. The first example illustrates that Lemmas 1-2 do not generally hold true without the IRC condition. As a consequence, multiple stable and strategy-proof rules exist in this example.

Example 1. Let $D=\left\{d_{1}, d_{2}\right\}, H=\{h\}$, and $X=\left\{x_{1}, x_{2}\right\}$, where for each $i \in\{1,2\}, x_{i}$ is a contract between $d_{i}$ and $h$. Suppose that each doctor $d_{i}$ has a preference relation with $x_{i} \succ_{d_{i}} \varnothing$, and that hospital $h^{\prime}$ s choice function is such that $C_{h}\left(\left\{x_{1}\right\}\right)=x_{1}, C_{h}\left(\left\{x_{2}\right\}\right)=x_{2}$, but $C_{h}\left(\left\{x_{1}, x_{2}\right\}\right)=\varnothing$. It is immediate to check $C_{h}(\cdot)$ violates the IRC condition. Note also that at this $\left(C_{H}(\cdot), \succ_{D}\right)$, allocation $\left\{x_{1}\right\}$ is not blocked by any coalition, although it is weakly blocked by $\left(h,\left\{x_{1}, x_{2}\right\}\right) .{ }^{27}$ That is, the conclusion of Lemma 1 fails to hold. Consequently, both $\left\{x_{1}\right\}$ and $\left\{x_{2}\right\}$ are stable at this profile, and the conclusion of Lemma 2 also fails. Lastly, define for each $i \in\{1,2\}$ a rule $f^{i}(\cdot)$ by

$$
f^{i}\left(\succ_{D}^{\prime}\right)=\left\{\begin{aligned}
\left\{x_{i}\right\} & \text { if } x_{i} \succ_{d_{i}}^{\prime} \varnothing, \\
\left\{x_{j}\right\} & \text { if } \varnothing \succ_{d_{i}}^{\prime} x_{i} \text { and } x_{j} \succ_{d_{j}} \varnothing \\
\varnothing & \text { otherwise, }
\end{aligned}\right.
$$

where $j \in\{1,2\}-\{i\}$. Then it can be easily checked that both $f^{1}(\cdot)$ and $f^{2}(\cdot)$ are stable and strategy-proof.

The following example shows that in general, the cumulative offer process may not lead to the doctor-optimal stable rule, even if it exists and is strategy-proof.

Example 2. Let $D=\left\{d_{1}, d_{2}\right\}, H=\{h\}$, and $X=\left\{x_{i}, y_{i}\right\}_{i \in\{1,2\}}$, where $x_{i}$ and $y_{i}$ denote

\footnotetext{
${ }^{27}$ The second requirement of weak blocking is vacuously satisfied since $C_{h}\left(\left\{x_{1}, x_{2}\right\}\right)=\varnothing$.
} 
two distinct contracts between $d_{i}$ and $h$. The hospital's choice function is induced by

$$
\succ_{h}:\left\{x_{1}, x_{2}\right\} \succ_{h}\left\{y_{1}, x_{2}\right\} \succ_{h} \varnothing \text {. }
$$

In this market, the doctor optimal stable rule $X^{*}(\cdot)$ exists:

$$
X^{*}\left(\succ_{D}\right)=\left\{\begin{array}{cl}
\left\{x_{1}, x_{2}\right\} & \text { if } x_{1}=\max \left\{x_{1}, y_{1}, \varnothing\right\} \text { and } x_{2} \in \operatorname{Ac}\left(\succ_{d_{2}}\right) \\
\left\{y_{1}, x_{2}\right\} & \text { if } y_{1}=\max \left\{x_{1}, y_{1}, \varnothing\right\} \text { and } x_{2} \in \operatorname{Ac}\left(\succ_{d_{2}}\right) \\
\varnothing & \text { otherwise, }
\end{array}\right.
$$

where the maximums are taken with respect to $\succ d_{1}$. Thus, our Theorem 2 tells that $X^{*}(\cdot)$ is the unique candidate for a stable and strategy-proof rule, and indeed, it is strategyproof. To see this, note that $X^{*}(\cdot)$ selects the best allocation for doctor $d_{1}$ subject to the individual rationality constraints for $d_{2}$ and $h$. Hence, doctor $d_{1}$ has no incentive to misreport. Doctor $d_{2}$ cannot manipulate $X^{*}(\cdot)$ either, since (i) it depends on $\succ_{d_{2}}$ only through whether $x_{2} \in \operatorname{Ac}\left(\succ_{d_{2}}\right)$ or not, and (ii) $X^{*}\left(\succ_{D}\right) \ni x_{2}$ only when $x_{2} \in \operatorname{Ac}\left(\succ_{d_{2}}\right)$.

While the doctor-optimal stable rule exists and is strategy-proof, it is not induced by the (simultaneous-offer) cumulative offer process as defined in Definition $6 .{ }^{28}$ To see this, let $\succ_{D}$ be such that

$$
\begin{aligned}
& \succ_{d_{1}}: y_{1} \succ_{d_{1}} x_{1} \succ_{d_{1}} \varnothing, \text { and } \\
& \succ_{d_{2}}: y_{2} \succ_{d_{2}} x_{2} \succ_{d_{2}} \varnothing .
\end{aligned}
$$

With this $\succ_{D}$, the (simultaneous-offer) cumulative offer returns $\left\{x_{1}, x_{2}\right\} \neq X^{*}\left(\succ_{D}\right)$.

\footnotetext{
${ }^{28}$ More precisely, what we check below is that not all cumulative offer processes are strategy-proof, since those processes fail to be order-independent in this example and hence, the cumulative offer process is not well-defined as a single rule (cf. footnote 23). Actually, there exists a (single-offer) cumulative offer process that induces $X^{*}(\cdot)$.
} 
The last example shows that non-wastefulness as defined in Appendix B does not necessarily follow from stability in the absence of the IRC condition.

Example 3. Let $D=\left\{d_{1}, d_{2}\right\}, H=\left\{h_{1}, h_{2}\right\}$, and $X=\left\{x_{1}, x_{2}\right\}$, where for each $i \in\{1,2\}$, $x_{i}$ is a contract between $d_{i}$ and $h_{i}$. Suppose that each $d_{i}$ has a preference relation such that $x_{i} \succ_{d_{i}} \varnothing$, and each $h_{i}$ has a choice function $C_{h_{i}}(\cdot)$ such that $C_{h_{i}}\left(\left\{x_{1}, x_{2}\right\}\right)=x_{i}$ and $C_{h_{i}}\left(X^{\prime}\right)=\varnothing$ for all $X^{\prime} \subsetneq X$. Then, allocation $X^{\prime}=\varnothing$ is wasteful but stable. 


\section{References}

Abdulkadiroglu, A., P. A. Pathak, And A. E. Roth (2009): “Strategy-Proofness versus Efficiency in Matching with Indifferences: Redesigning the NYC High School Match," American Economic Review, 99, 1954-1978.

AfacAn, M. O. (2014): "Some Further Properties of the Cumulative Offer Process," mimeo.

— (2015): "Characterizations of the Cumulative Offer Process," mimeo.

Afacan, M. O. And B. Turhan (2015): “On Relationships between Substitutes Conditions," Economics Letters, 126, 10-12.

Alcalde, J. AND S. BARberÀ (1994): “Top Dominance and the Possibility of StrategyProof Stable Solutions to Matching Problems," Economic Theory, 4, 417-435.

ANNO, H. AND M. KURINO (2014): “Second-best Incentive Compatible Allocation Rules for Multiple-type Indivisible Objects," mimeo.

AYGÜN, O. AND T. SÖNMEZ (2012): "The Importance of Irrelevance of Rejected Contracts in Matching under Weakened Substitutes Conditions," mimeo.

_ (2013): "Matching with Contracts: Comments," American Economic Review, 103, 2050-2051.

Chen, P., M. Egesdal, M. Pycia, And M. B. Yenmez (2014): “Manipulability of Stable Mechanisms," American Economic Journal: Microeconomics, forthcoming.

Dimakopoulos, P. D. AND C.-P. Heller (2014): “Matching with Waiting Times: The German Entry-Level Labour Market for Lawyers," mimeo. 
Dubins, L. E. And D. A. Freedman (1981): “Machiavelli and the Gale-Shapley Algorithm," American Mathematical Monthly, 88, 485-491.

ERDIL, A. (2014): “Strategy-Proof Stochastic Assignment," Journal of Economic Theory, 151, $146-162$.

Gale, D. And L. S. Shapley (1962): “College Admissions and the Stability of Marriage," American Mathematical Monthly, 69, 9-15.

Hatfield, J. W. AND F. Kojima (2010): "Substitutes and Stability for Matching with Contracts," Journal of Economic Theory, 145, 1704-1723.

Hatfield, J. W. AND S. D. Kominers (2014): “Hidden Substitutes," mimeo.

Hatfield, J. W., S. D. Kominers, And A. WestKamp (2015): “Stability, StrategyProofness, and Cumulative Offer Mechanisms," mimeo.

Hatfield, J. W. And P. R. Milgrom (2005): "Matching with Contracts," American Economic Review, 95, 913-935.

Hirata, D. AND Y. KasuYa (2014): “Cumulative Offer Process is Order-Independent," Economics Letters, 124, 37-40.

Kelso, A. S. AND V. P. CRAWford (1982): “Job Matching, Coalition Formation, and Gross Substitutes," Econometrica, 50, 1483-1504.

Kesten, O. (2010): "School Choice with Consent," Quarterly Journal of Economics, 125, $1297-1348$.

Kesten, O. And M. Kurino (2013): “Do Outside Options Matter in School Choice? A New Perspective on the Efficiency vs. Strategy-Proofness Trade-off," mimeo.

Kominers, S. D. AND T. SÖnMeZ (2013): “Designing for Diversity in Matching," mimeo. 
— (2014): "Matching with Slot-Specific Priorities: Theory," Theoretical Economics, forthcoming.

PAthaK, P. A. And T. SÖnmez (2013): "School Admissions Reform in Chicago and England: Comparing Mechanisms by Their Vulnerability to Manipulation," American Economic Review, 103, 80-106.

RotH, A. E. (1982): “The Economics of Matching: Stability and Incentives," Mathematics of Operations Research, 7, 617-628. (1984): "Stability and Polarization of Interests in Job Matching," Econometrica, 52, $47-58$.

SAKAI, T. (2011): “A Note on Strategy-Proofness from the Doctor Side in Matching with Contracts," Review of Economic Design, 15, 337-342. 